\title{
Regulation of the cAMP Level in the Yeast Saccharomyces cerevisiae: the Glucose-induced cAMP Signal Is Not Mediated by a Transient Drop in the Intracellular pH
}

\author{
By JOHAN M. THEVELEIN, ${ }^{1}$ * MONIQUE BEULLENS, ${ }^{1}$ \\ FAN NY HONSHOVEN, ${ }^{1}$ GREET HOEBEECK, ${ }^{1}$ \\ KATRIEN DETREMERIE, ${ }^{1}$ BERNHARD GRIEWEL, ${ }^{2}$ \\ JAN A. DEN HOLLANDER ${ }^{3}$ AND ARNOLD W. H. JANS ${ }^{2}$ \\ ${ }^{1}$ Laboratorium voor Cellulaire Biochemie, Katholieke Universiteit te Leuven, Kardinaal \\ Mercierlaan 92, B-3030 Leuven - Heverlee, Belgium \\ ${ }^{2}$ Max-Planck-Institut für Systemphysiologie, Rheinlanddamm 201, D-4600 Dortmund 1, FRG \\ ${ }^{3}$ Philips Medical Systems, PO Box 218, 5600 MD Eindhoven, The Netherlands
}

(Received 1 December 1986; revised 3 March 1987)

\begin{abstract}
Addition of glucose to derepressed cells of the yeast Saccharomyces cerevisiae is known to cause a rapid, transient increase in the cAMP level, which lasts for 1-2 min and induces a cAMPdependent protein phosphorylation cascade. The glucose-induced cAMP signal cannot be explained solely on the basis of an increased ATP level. Transient membrane depolarization and transient intracellular acidification have been suggested as possible triggers for the CAMP peak. Addition of glucose to cells in which the plasma membrane had been depolarized still produced the increase in the cAMP level excluding membrane depolarization as the possible trigger. Using in vivo ${ }^{31} \mathrm{P}$ NMR-spectroscopy we followed phosphate metabolism and the time course of the drop in the intracellular $\mathrm{pH}$ after addition of glucose with a time resolution of $15 \mathrm{~s}$. Under aerobic conditions the initial $\mathrm{pH}$ and ATP level were high. On addition of glucose, they both showed a rapid, transient drop, which lasted for about $30 \mathrm{~s}$. Under anaerobic conditions, the initial $\mathrm{pH}$ and ATP level were low and on addition of glucose they both increased relatively slowly compared to aerobic conditions. Several conditions were found in which the $\mathrm{pH}$ drop which occurs under aerobic conditions could be blocked completely without effect on the cAMP signal or without completely preventing it: addition of $\mathrm{NH}_{4} \mathrm{Cl}$ together with glucose at high extracellular $\mathrm{pH}$ and addition of a low concentration of glucose before a high concentration. Also, when glucose was added twice to the same cells no consistent relationship was observed between the $\mathrm{pH}$ drop and the cAMP peak. These results appear to exclude transient intracellular acidification as the trigger for the cAMP signal. Hence, we conclude that the effect of glucose cannot be explained on the basis of effects known to be caused by the membrane depolarizing compounds which cause increases in the cAMP level. A new, more specific kind of interaction appears to be involved.
\end{abstract}

\section{INTRODUCTION}

Addition of glucose to derepressed yeast cells causes a rapid transient increase in the cAMP level (Van der Plaat, 1974) which triggers a cAMP-dependent protein phosphorylation cascade similar to the well-known, hormone-induced phosphorylation cascades in mammalian cells (for reviews see Thevelein, 1984; Holzer, 1984). Based on the known effects of membrane depolarizing compounds two hypotheses have been proposed for the mechanism triggering the glucose-induced cAMP signal. The first was based on the observation that addition of glucose

Abbreviation: DNP, 2,4-dinitrophenol. 
itself causes a transient depolarization of the plasma membrane (Kovac \& Varecka, 1981; Mazon et al., 1982), and this was suggested to be the trigger for the transient cAMP increase (Mazon et al., 1982; Holzer, 1984). The second was based on the fact that the membrane depolarizing compounds that enhance the cAMP level in yeast also lower the intracellular $\mathrm{pH}$. Because of the different $\mathrm{pH}$ optima of adenyl cyclase $(\mathrm{pH} \mathrm{6)}$ and phosphodiesterase $(\mathrm{pH} 8)$ a lowering of the intracellular $\mathrm{pH}$ was expected to raise the cAMP level (Londesborough, 1977). Since addition of glucose to (glucose-repressed) yeast cells causes a transient drop in the intracellular pH (den Hollander et al., 1981), it was suggested that a similar drop in derepressed yeast cells might trigger the glucose-induced cAMP signal (Busa \& Nuccitelli, 1984). In recent publications (Caspani et al., 1985; Valle et al., 1986; Purwin et al., 1986) this hypothesis was supported on the basis of the similarity between the glucose effect and the effect of agents that lower the intracellular $\mathrm{pH}$ in yeast.

In the present paper we present evidence against both hypotheses. The effect of glucose is shown to be unrelated to the effect of membrane depolarizing compounds and we suggest that it involves a different mechanism.

\section{METHODS}

Yeast strain and culture conditions. The Y55 yeast strain and the culture conditions used were the same as described by Thevelein et al. (1987).

Incubation conditions. The incubation conditions were basically as described by Thevelein et al. (1987). Cells were suspended ( $300 \mathrm{mg}$ wet wt $\mathrm{ml}^{-1}$ ) in $25 \mathrm{~mm}-\mathrm{MES} / \mathrm{NaOH}$ buffer, $\mathrm{pH} 6$, which was bubbled with pure $\mathrm{O}_{2}$ ('aerobic conditions') or pure $\mathrm{N}_{2}$ ('anaerobic conditions'). The incubation conditions in the cAMP determination experiments and in the NMR experiments were the same. It was technically not possible to take samples for cAMP determination during the NMR experiments. The experiments labelled 'shake culture' were done at low cell density as described by Thevelein et al. (1987). In all experiments, the cells were preincubated at $25^{\circ} \mathrm{C}$ for $10 \mathrm{~min}$ under the appropriate conditions. Incubation at high external $\mathrm{pH}$ was done in $25 \mathrm{~mm}-\mathrm{Tris} / \mathrm{HCl}$ buffer, pH 8 or 9.

cAMP determination. This was done as described by Thevelein et al. (1987).

In vivo ${ }^{31} P$-NMR spectroscopy. In vivo NMR spectra were taken as a function of time as described by Thevelein et al. (1987).

Reproducibility of results. All experiments were repeated at least twice with consistent results. Representative results are shown.

\section{RESULTS}

To investigate whether or not the glucose-induced cAMP increase could be explained by the increased ATP level, we did experiments in which cells kept under anaerobic conditions were suddenly supplied with oxygen, or oxygenated cells were given glycerol or acetate (at $\mathrm{pH} 6$ ). In none of these cases was a significant increase in the cAMP level observed (results not shown), indicating that under aerobic conditions the ATP level is not limiting cAMP synthesis. Evidence has been presented, however, that under anaerobic conditions the ATP level might be limiting (Thevelein et al., 1987). The glucose-induced cAMP increase was also significantly retarded under anaerobic conditions compared to aerobic conditions (Fig. 1) and this correlated with the slower increase in the ATP level (Fig. $3 a, b$ ).

Dinitrophenol (DNP) causes an increase in the cAMP level in yeast (Trevillyan \& Pall, 1979; Mazon et al., 1982; Thevelein et al., 1987). It was shown to depolarize the plasma membrane in our yeast strain and under our experimental conditions (Thevelein et al., 1987). When DNP was added at pH 6.25, a moderate increase in the cAMP level was obtained (cf. Thevelein et al., 1987). Addition of glucose to the same suspension caused a second and much greater increase in the cAMP level (Fig. 2). The experiment shown in Fig. 2 was done in shake culture at low cell density. In similar experiments done under aerobic and anaerobic conditions at high cell density, addition of glucose to a culture treated with DNP caused a second rapid increase in the cAMP level.

Using ${ }^{31} \mathrm{P}-\mathrm{NMR}$ spectroscopy we investigated phosphate metabolism and the time-course of the intracellular $\mathrm{pH}$ change after addition of glucose to derepressed yeast cells under aerobic 


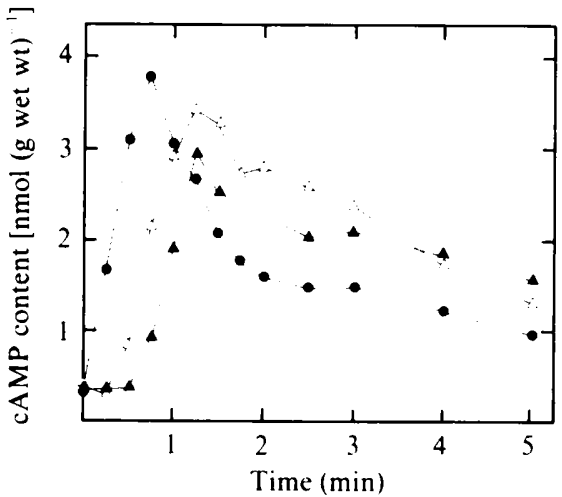

Fig. 1

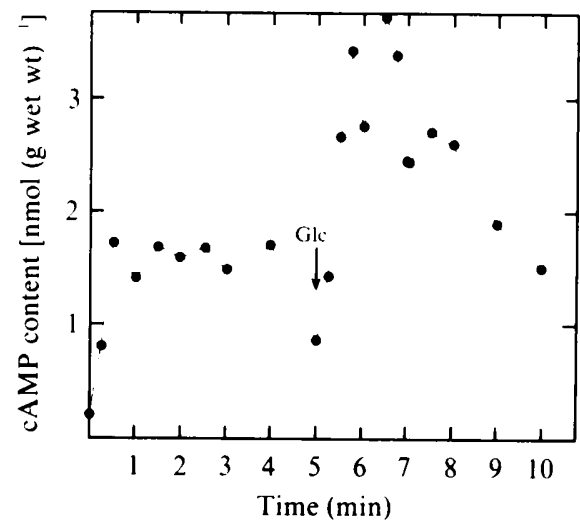

Fig. 2

Fig. 1. cAMP level after addition of $100 \mathrm{mM}$-glucose under aerobic and anaerobic conditions to a suspension of acetate-grown yeast cells in $25 \mathrm{~mm}-\mathrm{MES} / \mathrm{NaOH}$ buffer, $\mathrm{pH}$ 6. $\mathrm{O}$, Aerobic conditions; anaerobic conditions; $\triangle$, shake culture.

Fig. 2. cAMP level after addition of $2 \mathrm{mM}-\mathrm{DNP}$ at pH 6.25 and subsequent addition of glucose (100 mM after $5 \mathrm{~min}$, indicated by the arrow) to the same suspension.

(a)

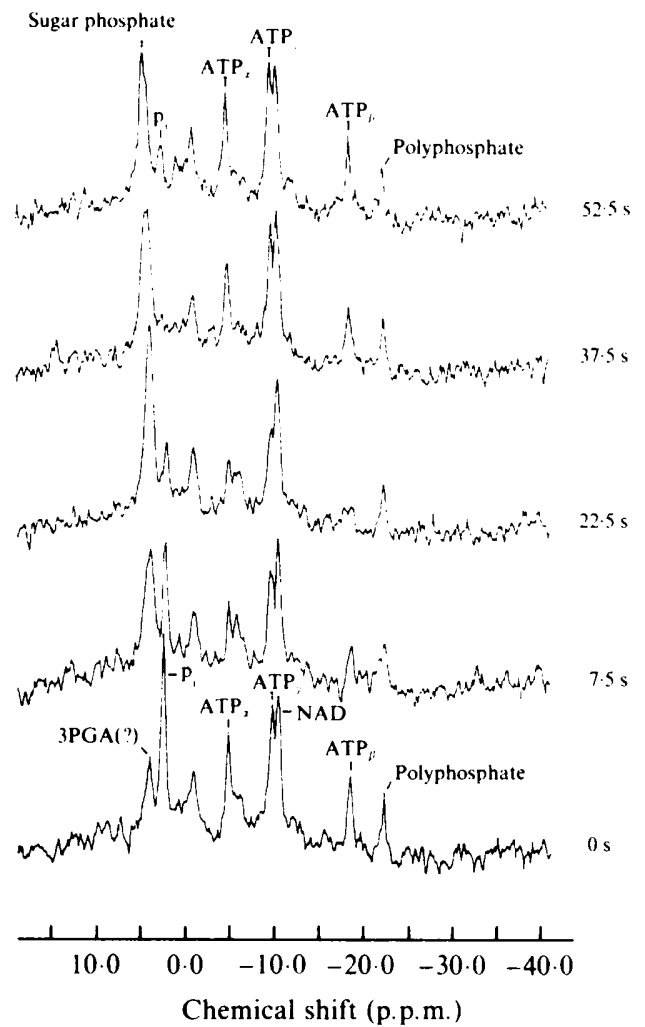

(b)

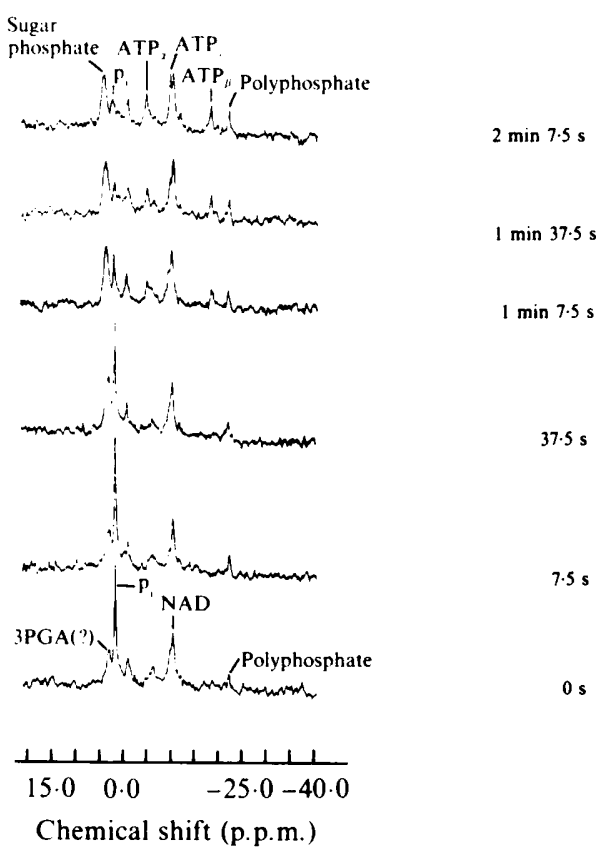

Fig. 3. ${ }^{31} \mathrm{P}-\mathrm{NMR}$ spectra of acetate-grown yeast cells before (time zero) and after addition of glucose under aerobic $(a)$ and anaerobic $(b)$ conditions. Spectra were accumulated in blocks of $15 \mathrm{~s}$; the spectra shown represent the mean value after $7.5 \mathrm{~s}, 22.5 \mathrm{~s}$ etc. The following peaks can be seen: $P_{i}$, free phosphate; $\mathrm{ATP}_{\alpha}, \mathrm{ATP}_{\beta} . \mathrm{ATP}_{\gamma}, \alpha, \beta$ and $\gamma$ phosphate groups of ATP; polyphosphate $(n \geq 4)$; sugar phosphate [this broad peak is mainly composed of three components: glucose 6-phosphate, fructose 6phosphate and fructose 1,6-bisphosphate (from left to right)]; NAD; the peak labelled 3PGA(?) probably corresponds to 3-phosphoglyceric acid (after addition of glucose this peak can be seen as a quickly disappearing shoulder at the right of the sugar phosphate peak). 


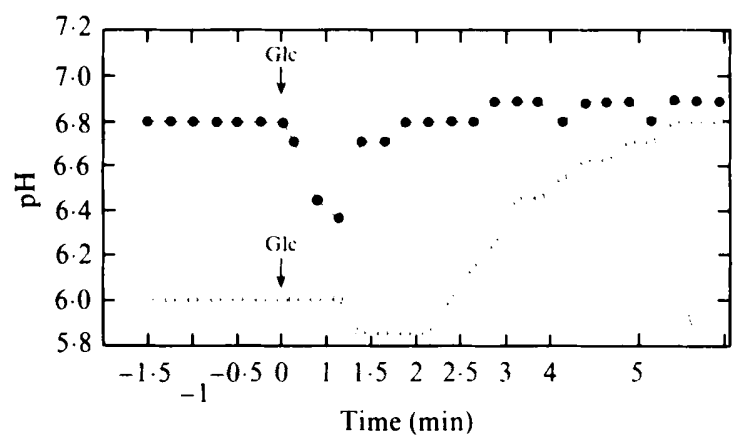

Fig. 4. Course of the intracellular pH after addition of $100 \mathrm{~mm}$-glucose (indicated by arrow) to acetategrown yeast cells under aerobic $(O)$ and anaerobic $(O)$ conditions.

(Fig. 3a) and anaerobic (Fig. $3 b$ ) conditions. NMR scans were accumulated in blocks of $15 \mathrm{~s}$; the first spectrum after addition of glucose therefore corresponds to the mean value at $7.5 \mathrm{~s}$ after addition of glucose. Under aerobic conditions the initial ATP level was high (Fig. $3 a$ ). Addition of glucose caused a transient drop (by about $70 \%$ ) in the ATP level and (by about $75 \%$ ) in the level of free phosphate. This coincided with a rapid buildup of sugar phosphates. The ATP level rapidly regained its initial value. Under anaerobic conditions, the initial ATP level was very low and increased rather slowly on addition of glucose. The buildup of sugar phosphates and the decrease of the phosphate level was clearly slower than under aerobic conditions (Fig. $3 b$ ).

From the position ('chemical shift') of the phosphate peak in the ${ }^{31} \mathrm{P}-\mathrm{NMR}$ spectrum, the intracellular $\mathrm{pH}$ can be determined (Gillies et al., 1982). The course of the intracellular $\mathrm{pH}$ after addition of glucose under aerobic and anaerobic conditions is shown in Fig. 4. Under aerobic conditions the initial $\mathrm{pH}$ was about $6 \cdot 7-7 \cdot 0$; on addition of glucose it showed a relatively small but reproducible decrease which lasted for about $30 \mathrm{~s}$. Under anaerobic conditions the initial $\mathrm{pH}$ was significantly lower (about 6.0-6.2); on addition of glucose it tended to decrease somewhat further before it increased to values similar to those present under aerobic conditions. This increase in the intracellular $\mathrm{pH}$ lagged somewhat behind the increase in the ATP level, under both aerobic and anaerobic conditions. Under anaerobic conditions, the intracellular $\mathrm{pH}$ before and just after glucose addition was much lower than the intracellular $\mathrm{pH}$ under aerobic conditions, even at the lowest value of the $\mathrm{pH}$ drop. The magnitude of the $\mathrm{pH}$ decrease observed under aerobic conditions was similar in different experiments. The initial $\mathrm{pH}$ present before the addition of glucose, however, was somewhat variable (e.g. see Fig. 5a). Therefore, and because of the small size of the $\mathrm{pH}$ drop, when the initial $\mathrm{pH}$ was rather high, the $\mathrm{pH}$ did not fall much below the initial $\mathrm{pH}$ observed in experiments where the initial $\mathrm{pH}$ was rather low (results not shown).

When $50 \mathrm{~mm}-\mathrm{NH}_{4} \mathrm{Cl}$ was added together with glucose at an external pH of 8 (Fig. $5 a$, aerobic conditions) or $\mathrm{pH} 9$ (results not shown) the $\mathrm{pH}$ drop was completely abolished. Apparently, this is due to the rapid influx of $\mathrm{NH}_{3}$ molecules which quickly become protonated once they are inside the cell because of the much lower intracellular $\mathrm{pH}$. Lower concentrations of $\mathrm{NH}_{4} \mathrm{Cl}(10$ and $25 \mathrm{~mm}$ ) did not prevent the pH drop completely. Fig. 5(a) also shows the variation of the initial intracellular $\mathrm{pH}$ between two duplicate experiments (before the addition of glucose, indicated by the arrow). Under conditions where the $\mathrm{pH}$ drop is completely abolished the cAMP response is delayed somewhat but certainly not completely inhibited (Fig. $5 b$ ). The delay might be due to unspecific inhibition of the cAMP synthesizing system by $\mathrm{NH}_{3}$ or $\mathrm{NH}_{4}^{+}$. It has been observed that many positively charged compounds inhibit cAMP synthesis in vivo (Francois et al., 1984; Thevelein \& Beullens, 1985). Anaerobically, a rapid increase in the intracellular pH

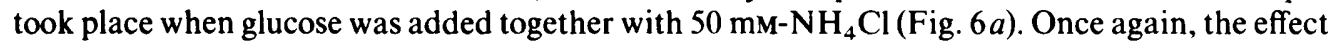
of $\mathrm{NH}_{4} \mathrm{Cl}$ was limited to a short delay in the initiation of the cAMP peak (Fig. $6 b$ ). (When similar experiments were done in shake culture at low cell density, inhibition by $\mathrm{NH}_{4} \mathrm{Cl}$ was more pronounced than under conditions identical to the NMR conditions. The reason for this is not known.) 

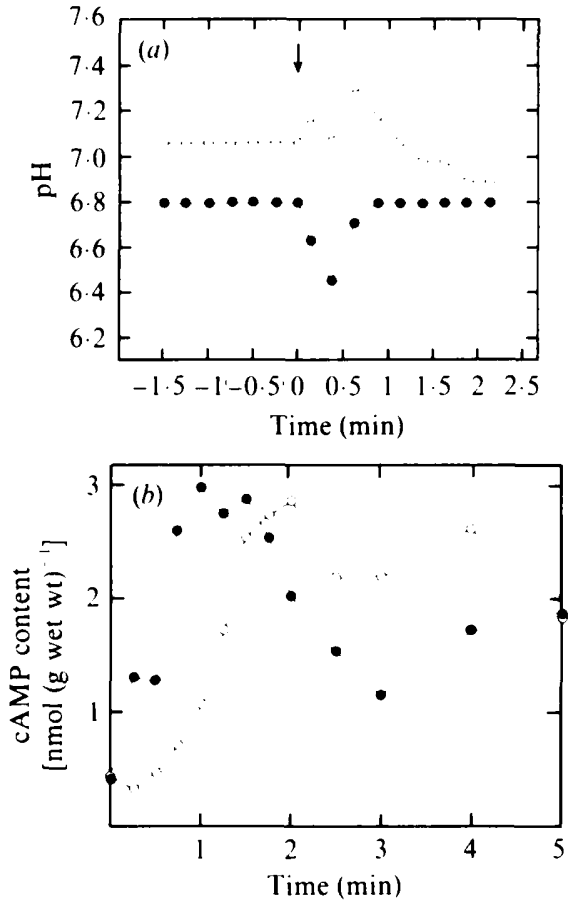

Fig. 5
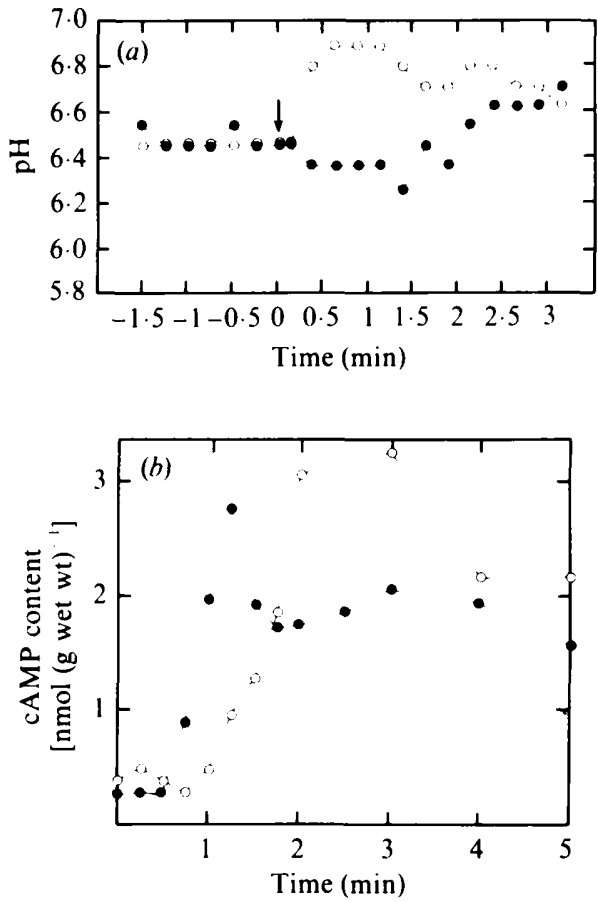

Fig. 6

Fig. 5. Course of the intracellular pH $(a)$ and the cAMP level $(b)$ after addition at time zero of $100 \mathrm{mM}$ glucose (O) or $100 \mathrm{~mm}$-glucose $+50 \mathrm{mM}-\mathrm{NH}_{4} \mathrm{Cl}(\mathrm{O})$ at high external pH $(25 \mathrm{~mm}$-Tris/ $\mathrm{HCl}, \mathrm{pH} 8)$ under aerobic conditions.

Fig. 6. Course of the intracellular pH $(a)$ and the cAMP level $(b)$ after addition at time zero of $100 \mathrm{mM}-$ glucose (O) or $100 \mathrm{~mm}$-glucose $+50 \mathrm{~mm}-\mathrm{NH}_{4} \mathrm{Cl}(\mathrm{O})$ at high external $\mathrm{pH}(25 \mathrm{~mm}-\mathrm{Tris} / \mathrm{HCl}, \mathrm{pH})$ under anaerobic conditions.

The $\mathrm{pH}$ drop, but not the cAMP increase, could also be prevented by adding a low concentration of glucose just before a high concentration. This is shown in Fig. 7 for $5 \mathrm{~mm}$ glucose followed $1 \mathrm{~min}$ later by $20 \mathrm{~mm}$-glucose : $5 \mathrm{mM}$-glucose induced a small cAMP increase, $20 \mathrm{~mm}$ a much larger one (Fig. 7 b); for the size of the pH drop in the two cases, the situation is just the opposite (Fig. $7 a$ ). Experiments with slightly differing conditions such as $8 \mathrm{~mm}$-glucose followed by $25 \mathrm{~mm}, 10 \mathrm{~mm}$ followed by $25 \mathrm{~mm}$ and $5 \mathrm{~mm}$ followed by $10 \mathrm{~mm}$ followed by $100 \mathrm{~mm}$, yielded results similar to those shown in Fig. 7.

Repeated addition of glucose to the same cells, washed and suspended each time in fresh buffer, causes new cAMP peaks which are smaller than the first one (Thevelein \& Beullens, 1985). Fig. 8(a) shows the pH drop in cells which were given glucose twice. After the first glucose addition, the cells were washed and resuspended in fresh buffer for about $5 \mathrm{~min}$. The initial pH before the second glucose addition was always higher, presumably because the cells were better energized. It can be seen from Fig. 8(a) that the second $\mathrm{pH}$ drop does not fall below the initial $\mathrm{pH}$ present before the first glucose addition. This is difficult to reconcile with the $\mathrm{pH}$ drop being the trigger for the glucose-induced cAMP peak since the peak was always observed after the second addition of glucose. This is shown in Fig. $8(b)$ for an experiment done under the same conditions as the NMR experiment. That the increased initial $\mathrm{pH}$ is not the cause of the lower second cAMP peak is corroborated by the fact that when, for each peak, DNP was added together with glucose (to lower the $\mathrm{pH}$ artificially to very low values), the second peak was still smaller than the first one (Fig. $8 b$ ). The decrease of the cAMP response therefore appears to be 

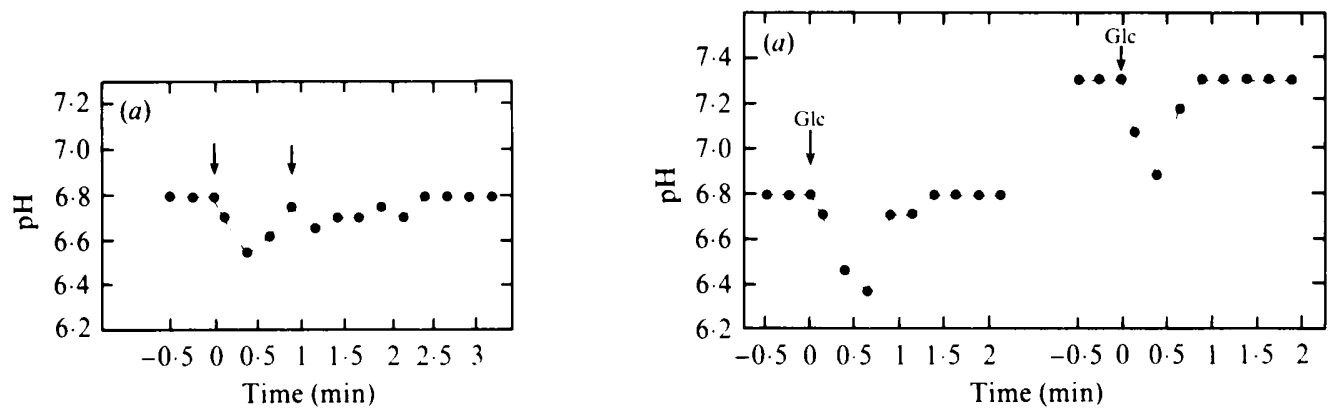

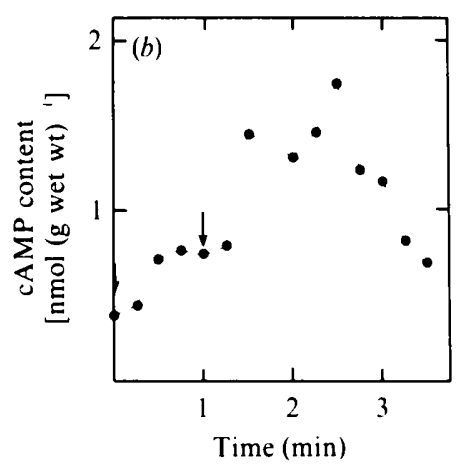

Fig. 7

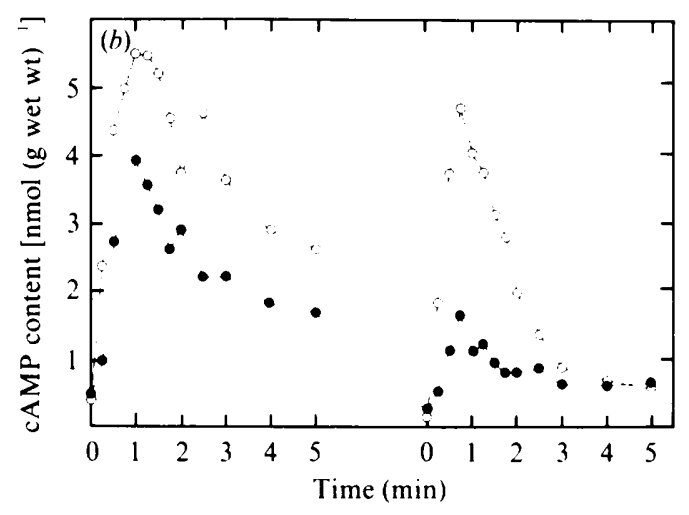

Fig. 8

Fig. 7. Course of the intracellular $\mathrm{pH}(a)$ and the cAMP level $(b)$ after addition of 5 mM-glucose at time zero (first arrow) followed by $20 \mathrm{~mm}$-glucose after $1 \mathrm{~min}$ (second arrow) under aerobic conditions.

Fig. 8. Reversibility of the glucose-induced $\mathrm{pH}$ drop $(a)$ and the glucose-induced cAMP peak $(b)$ under aerobic conditions. Glucose was added at time zero and the cells left in glucose for $60 \mathrm{~min}$. The intracellular $\mathrm{pH}$ and the cAMP levels were measured during the first minutes. After $60 \mathrm{~min}$, the cells were quickly chilled and washed with cold $25 \mathrm{mM}-\mathrm{MES} / \mathrm{NaOH}$ buffer, $\mathrm{pH} 6$, before the second glucose addition. In $(b)$ a replicate culture was given $100 \mathrm{~mm}$-glucose $+2 \mathrm{~mm}$-DNP $(\mathrm{O})$ instead of $100 \mathrm{~mm}$ glucose $(\mathbf{O})$.

due to inactivation of the cAMP synthesizing system (or activation of its breakdown system). Under anaerobic conditions similar results were obtained for the pH drop (Fig. $9 a$ ) and for the reversibility of the cAMP response (Fig. $9 b$ ). In this case, however, straightforward interpretation of the data is not possible because of possible limitation of cAMP synthesis by the low ATP level just before and just after addition of glucose. In addition, the difference in the initial $\mathrm{pH}$ might be important for at least part of the decrease in the cAMP peak. It is also possible that glucose causes changes in the cAMP synthesizing system, such as a shift in the $\mathrm{pH}$ optimum.

\section{DISCUSSION}

Our results confirm that the glucose-induced cAMP increase cannot be explained solely on the basis of the glucose-induced increase in the ATP level. Oxygenation of derepressed yeast cells does not cause an increase in the cAMP level, although it produces ATP levels which are about the same as those observed after addition of glucose (Fig. $3 a$ ). Apparently, the cells possess enough endogenous substrates to maintain such a high ATP level for at least 20 min when supplied with pure oxygen (results not shown). It cannot be excluded, however, that the glucoseinduced increase in the ATP level under anaerobic conditions is necessary for the cAMP 

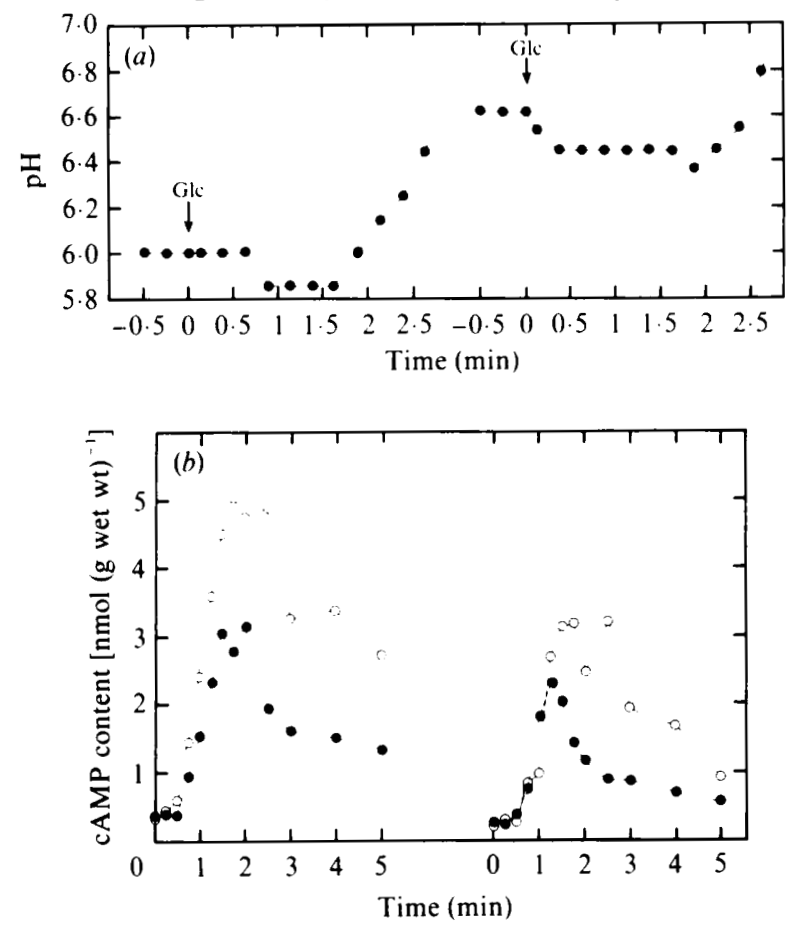

Fig. 9. Reversibility of the glucose-induced pH drop (a) and the glucose-induced cAMP peak $(b)$ under anaerobic conditions. Glucose was added at time zero and the cells left in glucose for $60 \mathrm{~min}$. The intracellular $\mathrm{pH}$ and the cAMP level were measured during the first minutes. After $60 \mathrm{~min}$, the cells were quickly chilled and washed with cold $25 \mathrm{~mm}-\mathrm{MES} / \mathrm{NaOH}$ buffer, $\mathrm{pH}$ 6, before the second glucose addition. In $(b)$ a replicate culture was given $100 \mathrm{~mm}$-glucose $+2 \mathrm{~mm}$-DNP $(O)$ instead of $100 \mathrm{~mm}-$ glucose (O).

increase to occur. This might be the cause of the short delay in the increase under anaerobic conditions (Fig. 1). In the accompanying paper (Thevelein et al., 1987) we provided evidence that the low ATP level under anaerobic conditions in the absence of glucose might be limiting for cAMP synthesis.

Two hypotheses have been proposed in the literature for the mechanism by which glucose induces the cAMP increase in derepressed yeast cells: the first one was based on the transient depolarization of the plasma membrane which occurs on addition of glucose (Mazon et al., 1982; Holzer, 1984); the second on the transient decrease of the intracellular pH (Busa \& Nuccitelli, 1984). We have presented evidence against membrane depolarization as a possible trigger for increases in the cAMP level (Thevelein et al., 1987). This is now confirmed for the glucoseinduced increase in the cAMP level (Fig. 2). Membrane depolarization before addition of glucose did not prevent the rapid increase in the cAMP level. Since addition of DNP instead of glucose also produces a cAMP increase under these conditions (Thevelein et al., 1987), the ATP level in the depolarized cells cannot have been a limiting factor.

The evidence that the stimulating effect of proton ionophores on the cAMP level is due to intracellular acidification (Thevelein et al., 1987), appeared to support the hypothesis of Busa \& Nuccitelli (1984) that a transient decrease in the intracellular $\mathrm{pH}$ could be the trigger for the cAMP signal. Addition of glucose to derepressed yeast cells causes a transient pH drop as had been found by den Hollander et al. (1981) for glucose-repressed $S$. cerevisiae and by Nicolay $e t$ al. (1982) for Zygosaccharomyces bailii. Recently, Caspani et al. (1985) and Valle et al. (1986) also provided evidence for the existence of a glucose-induced $\mathrm{pH}$ drop in derepressed $S$. cerevisiae cells, using classical $\mathrm{pH}$ determination methods. The $\mathrm{pH}$ drop is probably caused by the first and the third reactions of glycolysis, which are both proton-producing reactions. Apparently, the sudden massive initiation of glycolysis, as reflected by the rapid buildup of sugar phosphate, 
causes a partial depletion of the ATP level and concomitant generation of sufficient protons to acidify the cells. Recovery of the $\mathrm{pH}$ is probably brought about by the plasma membrane $\mathrm{H}^{+}-$ ATPase, which is itself also activated on addition of glucose to derepressed yeast cells (Serrano, 1983). Under anaerobic conditions the initial $\mathrm{pH}$ and the $\mathrm{pH}$ just after glucose addition were much lower than whatever $\mathrm{pH}$ under aerobic conditions. Under these conditions, however, cAMP synthesis is probably limited by the low ATP level.

Although the $\mathrm{pH}$ drop was reproducible with our strain, it was rather small. The magnitude of the $\mathrm{pH}$ drop apparently varies for different strains (e.g. see Valle et al., 1986). This might be due to differences in the vigour of the strains used, a more vigorous strain being able to recover faster from intracellular acidification than a less vigorous one. The activity of the plasma membrane ATPase and its degree of glucose-induced activation are probably crucial for this $\mathrm{pH}$ recovery. As a consequence of the small size of the $\mathrm{pH}$ drop and because of the variability of the initial $\mathrm{pH}$ of the cells before the addition of glucose, the lowest $\mathrm{pH}$ obtained in some experiments was not much below the initial $\mathrm{pH}$ present in other experiments. In addition, several conditions were found in which the $\mathrm{pH}$ drop was abolished without much effect on the cAMP peak, or in which there was no consistent relationship between the $\mathrm{pH}$ effect and the cAMP increase. This was true for addition of glucose together with $\mathrm{NH}_{4} \mathrm{Cl}$ at high extracellular pH (Fig. $5 a$ ), addition of a small amount of glucose before a larger concentration (Fig. $7 a$ ) and repeated addition of glucose to cells washed free from glucose (Fig. $8 a$ ).

Our results indicate that the glucose-induced cAMP peak in derepressed yeast cells cannot be explained on the basis of known effects of membrane depolarizing compounds, i.e. neither membrane depolarization nor intracellular acidification. This was tried before by several authors (Mazon et al., 1982; Holzer, 1984; Busa \& Nuccitelli, 1984; Caspani et al., 1985; Valle et al., 1986). Hence the effects of glucose and of proton ionophores do not share a common mechanism. Instead, we suggest that the effect of glucose is based on a more specific interaction which might be analogous to the mechanism involved in the generation of the hormone-induced cAMP signal in mammalian cells. Apparently, one of the components of the mechanism is glucose repressible: glucose-repressed yeast cells do not show a cAMP peak when given glucose (unpublished results). This component also appears to be inactivated rapidly on addition of glucose (Figs $8 b$ and $9 b$; Thevelein \& Beullens, 1985). Hence, the cAMP signal itself is probably controlled by glucose-induced inactivation (also called 'catabolite inactivation': Holzer, 1976), just like the enzymes for which it triggers inactivation (e.g. fructose bisphosphatase).

J.M.T. gratefully acknowledges receipt of a fellowship from the Belgian National Fund for Scientific Research ('Research Associate'). We thank Dr M. C. Loureiro-Dias, Professor N. van Uden and Dr D. Kuschmitz for stimulating discussions. We are also indebted to Professor $\mathbf{R}$. Kinne for critical reading of the manuscript. This work was supported in part by grants from the Belgian National Fund for Scientific Research, the Research Fund of the KU Leuven and the North Atlantic Treaty Organization (grant no. 5-2-05/RG 86/174).

\section{REFERENCES}

Busa, W. B. \& Nuccitelli, R. (1984). Metabolic regulation via intracellular pH. American Journal of Physiology 246, R409-R438.

Caspani, G., Tortora, P., Hanozet, G. M. \& GUERRITORE, A. (1985). Glucose-stimulated cAMP increase may be mediated by intracellular acidification in Saccharomyces cerevisiae. FEBS Letters 186, 75-79.

Francois, J., Van Schaftingen, E. \& Hers, H. G. (1984). The mechanism by which glucose increases fructose-2,6-bisphosphate concentration in Saccharomyces cerevisiae. A cyclic-AMP-dependent activation of phosphofructokinase 2. European Journal of Biochemistry 145, 187-193.

Gillies, R. J. Alger, J. R., Den Hollander, J. A. \& ShulmaN, R. G. (1982). Intracellular pH measured by NMR: methods and results. In Intracellular $p H$ : its Measurement, Regulation and Utilization in Cellular Functions, pp. 79-104. Edited by R. Nuccitelli \& D. Deamer. New York: Alan R. Liss.

DEN Hollander, J. A., Ugurbil, K., BRown, T. R. \& Shulman, R. G. (1981). "P-NMR studies of the effect of oxygen upon glucolysis in yeast. Biochemistry 20, 5871-5880.

Holzer, H. (1976). Catabolite inactivation in yeast. Trends in Biochemical Sciences 1, 178-181.

HolzER, H. (1984). Mechanism and function of reversible phosphorylation of fructose 1,6-bisphosphatase in yeast. In Molecular Aspects of Cellular Regulation, vol. 3, pp. 143-154. Edited by P. Cohen. Amsterdam: Elsevier.

KovaC, L. \& VARECKA, L. (1981). Membrane poten- 
tials in respiration-deficient yeasts monitored by a fluorescent dye. Biochimica et biophysica acta 637, 209-216.

LONDESBOROUGH, J. (1977). Characterization of an adenosine $3^{\prime}: 5^{\prime}$-cyclic monophosphate phosphodiesterase from baker's yeast. Biochemical Journal 163, 467-476.

Mazon, M. J., Gancedo, J. M. \& Gancedo, C. (1982). Phosphorylation and inactivation of yeast fructose 1,6-bisphosphatase in vivo by glucose and by proton ionophores. A possible role for cAMP. European Journal of Biochemistry 127, 605-608.

Nicolay, K., Scheffers, W. A., Bruinenberg, P. M. \& KaPTEIN, R. (1982). Phosphorus-31 nuclear magnetic resonance studies of intracellular $\mathrm{pH}$, phosphate compartmentation and phosphate transport in yeast. Archives of Microbiology 133, 83-89.

Purwin, C., Nicolay, K., Scheffers, W. A. \& Holzer, H. (1986). Mechanism of control of adenylate cyclase activity in yeast by fermentable sugars and carbonyl cyanide $m$-chlorophenylhydrazone. Journal of Biological Chemistry 261, 8744-8749.

SERRANO, R. (1983). In vivo glucose activation of the yeast plasma membrane ATPase. FEBS Letters 156, 11-14.

Thevelein, J. M. (1984). Regulation of trehalose mobilization in fungi. Microbiological Reviews 48 , 42-59.

Thevelein, J. M. \& Beullens, M. (1985). Cyclic AMP and the stimulation of trehalase activity in the yeast Saccharomyces cerevisiae by carbon sources, nitrogen sources and inhibitors of protein synthesis. Journal of General Microbiology 131, 3199-3209.

Thevelein, J. M., Beullens, M., Honshoven, F., Hoebeeck, G., Detremerie, K., DEN Hollander, J. A. \& JANS, A. W. H. (1987). Regulation of the cAMP level in the yeast Saccharomyces cerevisiae: intracellular $\mathrm{pH}$ and the effect of membrane depolarizing compounds. Journal of General Microbiology 133, 2191-2196.

Trevillyan, J. M. \& Pall, M. L. (1979). Control of cyclic adenosine 3',5'-monophosphate levels by depolarizing agents in fungi. Journal of Bacteriology 138, 397-403.

Valle, E., Bergillos, L., Gascon, S., Parra, F. \& Ramos, $S$. (1986). Trehalase activation in yeasts is mediated by an internal acidification. European Journal of Biochemistry 154, 247-251.

Van der PlaAt, J. B. (1974). Cyclic 3',5'-adenosine monophosphate stimulates trehalose degradation in baker's yeast. Biochemical and Biophysical Research Communications 56, 580-587. 